$\mathrm{E}$ ste estudo está baseado em uma pesquisa (Siqueira Oliveira, Rabinovich, Santos, 1992) realizada com um número inicial de 60 crianças inscritas em um Centro de Saúde situado na região centrooeste da cidade de São Paulo. Essas crianças foram acompanhadas durante um ano em visitas domiciliares através de vários instrumentos (Anamnese Infantil e da Familia, roteiro para Observação do Ambiente doméstico, Organizadores de Spitz, Roteiro sobre Representação Materna do Desenvolvimento, Roteiro para Observação da relação MãeCriança e Ficha de Acompanhamento do Desenvolvimento do Ministério da Saúde). Os pais das crianças eram, em sua maior parte, de baixa renda, oriundos do nordeste $(92 \%)$, paulistas (37\%), mineiros $(11 \%)$, com escolaridade média de $5^{\mathrm{a}}$ série (da $1^{\mathrm{a}}$ à $4^{\mathrm{a}}$ série, $43,37 \%$; da $5^{\mathrm{a}}$ à $8^{\mathrm{a}}$ série $37,35 \%$, colegial:" $14,46 \%$ e superior: $4,88 \%$ ) Moravam em casas de propriedade familiar $(26,6 \%)$, casas alugadas (25\%), apartamentos $(20 \%)$, cortiços (20\%), barraco $(1,7 \%)$ e empregadas domésticas domiciliares no emprego $(6,7 \%)$. O presente estudo objetiva descrever o quarto de dormir do bebê e relacioná-lo ao modo de morar e à relação mãe-criança.

ARIĖS (1981) descreve como, no século XVII, o sentimento de infância ocorreu concomitantemente ao sentimento de família, e este, ao "chez soi": a casa demarcando o espaço privado do público. Segundo este autor, a organização da casa passou a corresponder a essa nova preocupação de defesa contra o mundo "Não havia mais camas por toda parte. As camas eram reservadas ao quarto de dormir, mobiliado de cada ladoda alcova com armários e nichos. Na França e na Itália a palavra chambre tendeu a se opor à palavra salle, antes quase sinônimos. Na Inglaterra, foi especificada através de um prefixo, dinning-room, bed-room, etc"(p.265).

Este autor e DUBY $(1990,1991 \mathrm{e}$ 1992) dirigiram um extenso estudo sobre o modo de vida dos gregos até hoje ressaltando como o modo de morar está intimamente relacionado ao modo de viver. DIBIE (1988) realizou um estudo etnológico sobre o quarto de dormir onde se pode ler: "O homem de Neanderthal, descoberto em Shanidar, no Iraque, deitado num leito de flores, é o primeiro a dar-nos um testemunho emocionante do que foi seguramente o seu leito de morte, fornecendo-nos também a prova do cuidado daqueles homens com o repouso, ainda que fosse o eterno"(p.16). Neste momento da história da humanidade o imaginário irrompe na percepção do real e o mito irrompe na visão do mundo (Morin, 1979). Na brecha entre o real e o imaginário, surge o mundo simbólico, o locus da cultura (WINNICOTT, 1982).

Para Morin (1978) o fogo cria o lar, lugar de proteção e de refúguio, permitindo o sono profundo do homem, ao contrário dos outros animais, cujo sonoé sempremarcado pelo alerta. Desse modo, o fogo pode ter favorecido o desenvolvimento do sonho.

Estudos comparativos (JOUVET, 1978) mostram que a questão do sono e do sonho está intimamente relacionada à segurança: o estado do sono paradoxal, onde o sonho aparece, é caracterizado por uma paralisia que só é admissível quando o animal se sente ao abrigo de qualquer agressão. A maioria dos animais sonhadores é constituída por carnívoros que dormem em segurança. Estes aspectos fizeram com que MOLES (1978) se perguntasse se não teria havido uma evolução fundamental do sono episódico no galho inseguro "ao recolhimento no quarto de janelas cerradas, na caverna fechada de todos os lados salvo numa direção"(p.161).

Em pesquisa por nós realizada (Rabinovich, 1992, no prelo) concluimos que a casa de quem não tem casa é definida pelo dormir, que seria, pois, a função mais importante para caracterizar a casa. No mesmo estudo, foi possível verificar que a falta de segurança durante o estado de desproteção que carracteriza o sonoé um dos principais problemas das pessoas que moram nestas condições.

Dentro de uma perspectiva intercultural, WHITING (1981) realizou um extenso estudo psico-cultural comparativo envolvendo crianças de três continentes. Definiu três tipos de culturas: as do berço, as da tipóia (como os Kung) e as do braço. Conclui que há relação entre o modo como as crianças são cuidadas quando acordadas e o modo como são cuidadas quando adormecidas, atribuin-

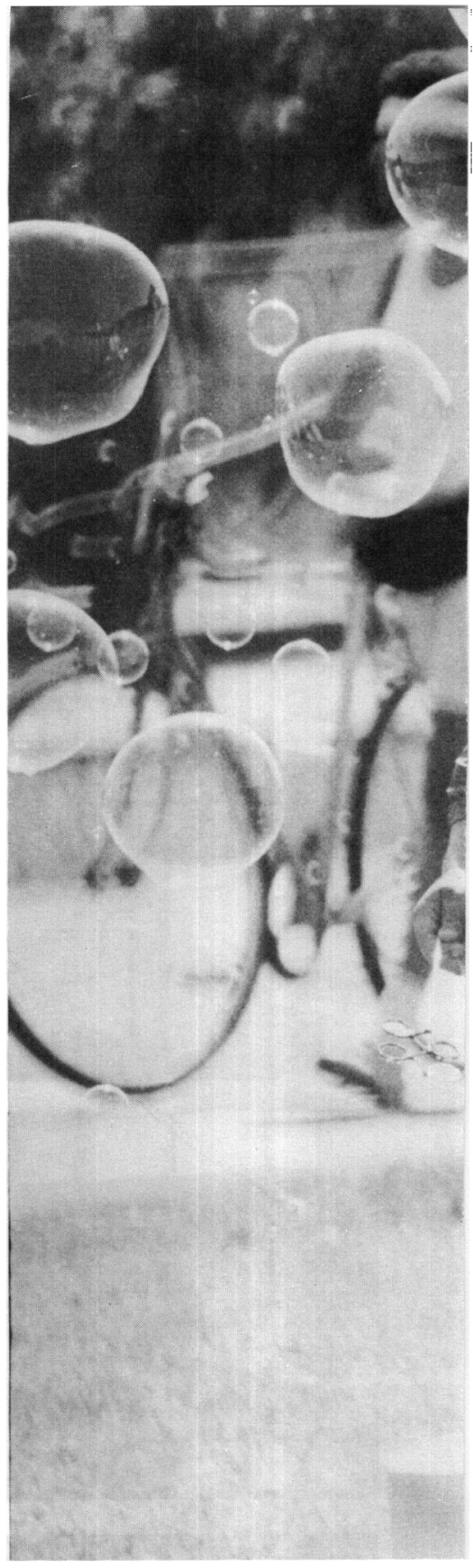




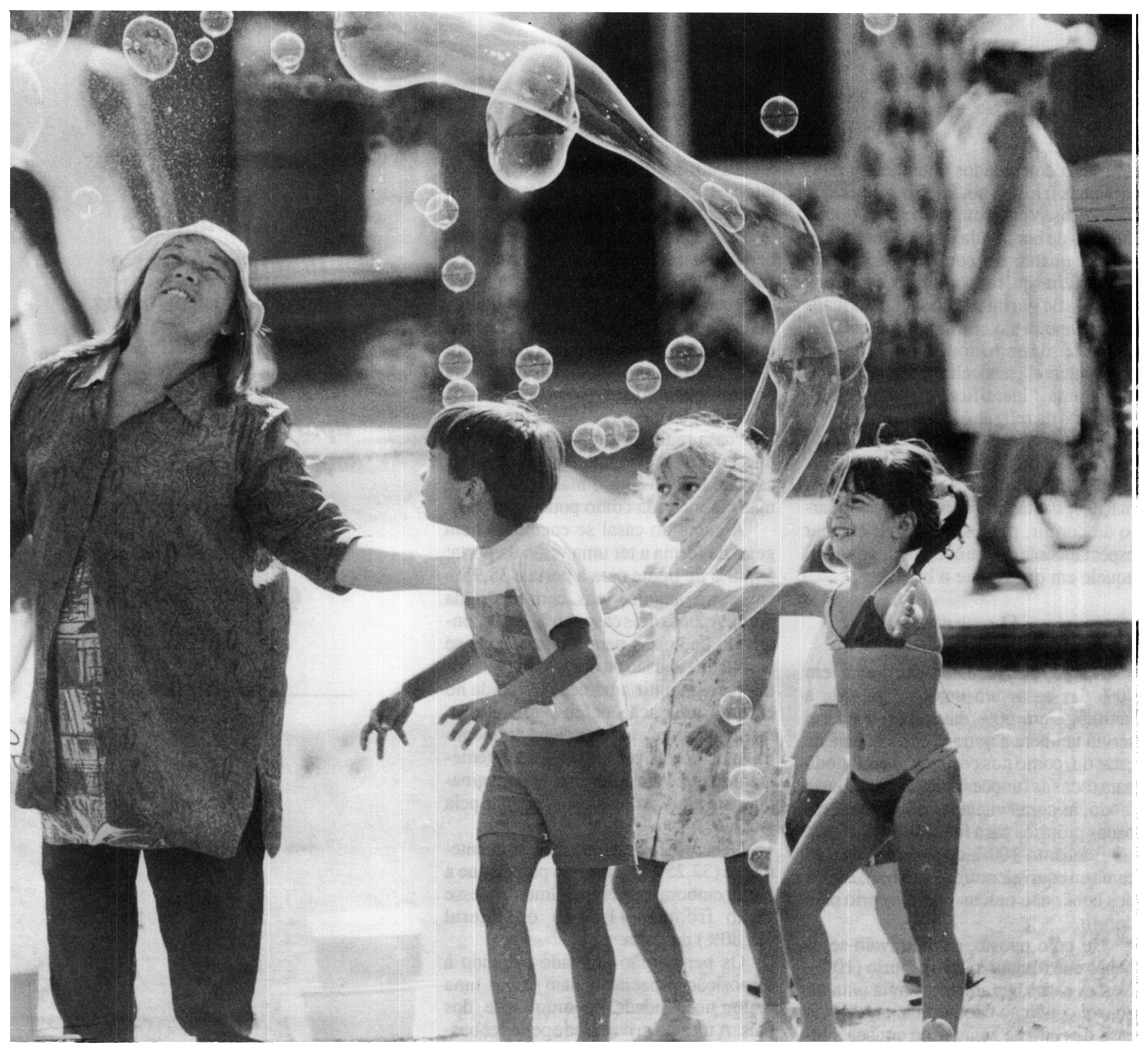

\section{de dormir e} mãe-criança

Elaine Pedreira Rabinovich

Bolsista CAPES, psicologa clínica, pesquisadora do Centro de Estudos do Crescimento e

Desenvolvimento do Ser Humano- CDH e mestrando em Psicologia Experimental/USP. 
do o tipo de cuidados à temperatura do mês mais frio do ano, ou seja, a questões climáticas. Verificou, além disso, que as culturas de berço e da tipóia diferem não apenas quanto ao contato físico entre mãe e criança mas também quanto à natureza de sua interação social Enquanto na primeira haveria um tipo de relação que ele denominou "dependência ambivalente", nas culturas da tipóia haveria uma "identificação simbiótica". Aspectos da religião destes dois tipos de cultura poderiam estar relacionados ao sistema de cuidados recebidos pelo bebê.

Em função desse conjunto de informação ressaltando a importância do quarto de dormir, propusemo-nos a enfocar especialmente dentre os cômodos da casa, aquele em que dorme o bebê.

\section{O quarto}

$\mathrm{Na}$ população estudada, havia em $90 \%$ das casas um quarto para toda a familia, e em $50 \%$ das casas, o quarto servia também a outras funções (sala de estar ou, como nos cortiços, um cômodo para todas as funções domésticas). Deste modo, às casas visitadas não tinham espaços próprios para funções específicas.

Enquanto $100 \%$ dos adultos tinham cama ou equivalente (colchonete), $23,3 \%$ dos bebês não tinham lugar próprio para dormir.

No pólo oposto, encontravam-se os bebês que tinham quarto próprio (10\%). Nesses casos, geralmente havia uma razoável condição econômica, mesmo no caso de filho de zelador ou em sua situaçãocongênere, porque alojamentos mais amplos ou com mais cômodos, na amostra pesquisada, significavam melhores condiçðes salariais e de moradia. Essas crianças com quarto próprio tinham também "canto próprio" (definido como o espaço delimitado pelo berço e no próprio berço).

A maioria - $90 \%$ - não tinha um quarto próprio. As crianças que dormiam no quarto dos pais tinham seus berços alinhados com a cabeceira da cama dos pais $(8 \%)$ e à esquerda desta $(76 \%)$. Esse arranjo pareceu ser determinado pela necessidade de cuidados noturnos realizados provavelmente pela mãe, de modo que a criança se situava próxima e ao lado desta.

A cama do casal geralmente estava localizada no meio do quarto $(57 \%)$ mas podia estar também no canto $(43 \%)$. A disposição central permitia livre movi- mentação dos dois lados, e a posição lateral ocorreu por falta de espaço; ou seja, quando não havia espaço suficiente, a cama era encostada num canto. Já o berço era preferencialmente colado à parede $(91 \%)$, aparentemente em busca de proteger o bebê. Embora os números não sejam conclusivos, nos três casos em que o berço ficou no meio do quarto havia alguma problemática afetiva na organização familiar (como no caso de uma mãe desorganizada emocionalmente, a casa muito arrumada, com problemas com a própria mãe, que morava na casa ao lado, e com o marido; ou outra mãe classificada como pouco afetiva).

A cama do casal se encontrava em geral de forma a ter uma visão da porta: $54,80 \%$ de frente para a porta e $38,95 \%$ em outro ângulo, mas com visão da porta. Apenas dois casos - $6 \%$ - se encontravam de costas para a porta. Pode-se pensar que a visão da porta, é fundamental, para garantir a percepção rápida no caso de uma ação defensiva. Curiosamente inúmeras vezes a cama se encontrava de costas para a janela: aparentemente o que vem pela porta era imaginado mais ameaçador que o que vem pela janela.

$O$ berço foi encontrado frequentemente $(32,25 \%)$ na mesma parede que a porta embora preferencialmente desse visão frontal $(41,03 \%)$ ou lateral $(25,80 \%)$ da porta.

Os berços não alinhados, devido à disposição espacial faziam supor uma maior necessidade de intimidade dos pais. A mesma privacidade pode ser buscada, embora raramente, $(3,33 \%)$ separando-se o quarto da criança por cortina, estante ou outro tipo de divisória.

Os móveis, muito padronizados, consistiam em camas de casal, armários e berços, algumas vezes criados-mudos ou outro móvel, camas de solteiro e beliches. Havia grande presença de tapetes.

Pode-se traçar o retrato do que seria o quarto "usual" de nossa pesquisa: é um quarto onde dormem pais e filhos, os pais numa cama de casal, o filho menor no berço, a partir de certa idade, pois até então dormiu com os pais no caso de haver irmão ocupando o berço (o que é usual, a não ser que seja o primogênito). Os irmãos mais no meio do quarto, de frente para a porta ou dando visão a ela, enquanto o berço do bebê está num canto, à esquerda e alinhando com a cabeceira da cama do casal. $O$ berço geralmente tem visão da porta mas pode se encontrar na mesma parede que a porta.

\section{"Curiosamente}

inúmeras vezes a

cama se encontrava

de costas para a janela:

aparentemente o que

vem pela porta era

imaginado mais

ameaçador que o

que vem pela

janela."

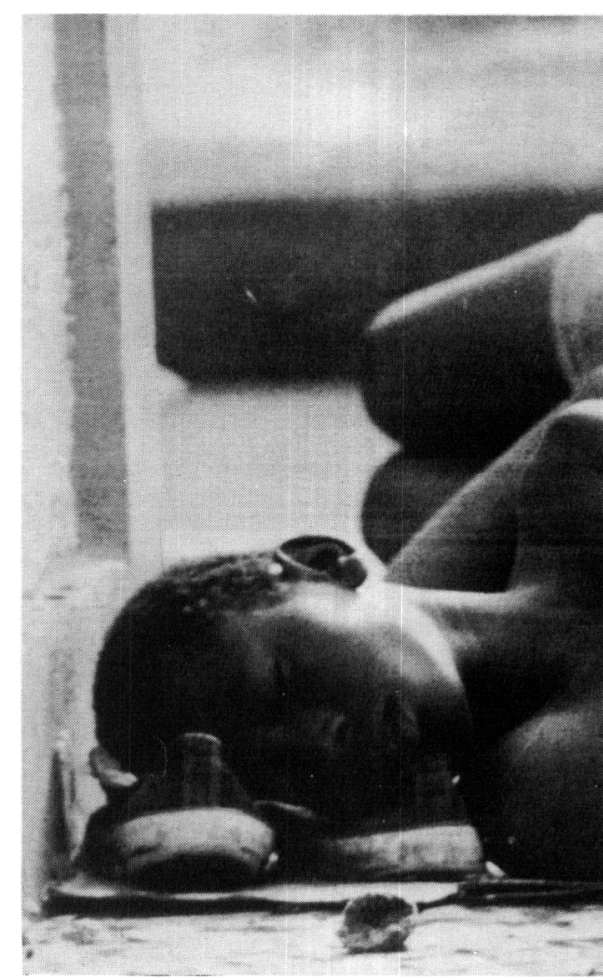


A organização do quarto nem sempre corresponde ao que ocorre ao dormir; a existência do berço não significa que o bebê lá durma. ( $10 \%$ não dormiam). Portanto, ao aspecto estático corresponde uma intecionalidade que tem de ser verificada ocorrer ou não na prática.

A descrição do quarto suscita várias questões. A não ordenação por funções, ou seja o quarto que serve a várias funções, e o quarto não como local da privacidade e intimidade remetem à organização das casas oitocentistas citadas por Ariès (1981). Obtivemos um índice de uma pessoa e meia por cama e de metade das casas sem portas entre os cômodos. Esse modo de dormir e de viver coletivizado se contrapōe a valores privatizados, ou seja, parte de nossa população dorme em condições semelhantes à época pré-moderna, em uma época pós-moderna na qual participam totalmente.

Porém, através de uma disposição de móveis que de algum modo isola o casal dos filhos, pode-se observar a procura da privacidade do casal.

Fatores sócio-econômicos parecem determinar tanto a ausência de berço quanto a presença de quarto próprio do bebê. Contudo, a presença do berço não significa que a criança durma nela e condições sócio-econômicas semelhan- tes determinam arranjos espaciais diversos; isto é, a relação da família, a sua subjetividade, faz com sejam privilegiados certos aspectos ante outros.

Do lado oposto, surpreende a regularidade do arranjo espacial do quarto de dormir sugerindo pré-disposições (HINDE, 1987) presentes nesse momento de abandono. Podemos citar: a proteção da cabeça; a cabeça virada para a porta; a mulher à esquerda do homem; o bebê à esquerda da mulher; o berço do bebê no canto.

Portanto, o estudo do modo de dormir aponta para uma racionalidade no modo de arranjar o quarto ao lado de uma emotividade que decorre do modo de usar tal disposição. Aponta para a hipótese de predisposições(Hinde, 1987) para tal arranjo concomitantemente à presença de fatores sócio-econômicos e culturais que determinam tanto o modo de dormir quanto o modo de vida.

\section{0 berço e os enfeites}

$O$ berço pode ser pensado como o espaço individual, privativo, do bebê. Pode ser considerado um índice de privatização da criança.

Os enfeites, para MORRIS (1967) são um equivalente rigoroso do que fazem outra espécies territoriais, quando depositam os seus cheiros pessoais ou os seus excrementos nas proximidades das respectivas tocas. Para esse autor, o colecionador é uma pessoa que sente uma necessidade anormal de definir dessa forma orespectivo território habitacional.

O berço e o cantinho do bebê são projetos espaciais dos pais quanto ao modo como a criança vai ocupar o seu lugar no mundo. Fazem parte do "espaço potencial", isto é, o espaço representacional do desenvolvimento da criança.

Com a sedentarização, cada macho, tornando-se chefe de família, passou a ter de defender a sua própria habitação no interior da colônia (MORRIS, 1967). Para EIBL-EIBELFELDT (1974), a territorialidade é a intolerância ligada a espaço, à defesa do espaço contra os de fora, o dominio de um grupo sobre outro naquele lugar. Através de inúmeras descrições baseadas em filmagens de cenas naturais, ilustra quer a agressividade. quer a demarcação territorial dos povos de caça-coleta, como os !Kung, artravés dos bandos e suas redes sociais. Conclui que muitos padrões agressivos são adaptaçסes fillogenéticas ritualizadas a serviço do espaçamento e do controle de agressão.

$O$ berço pode ser considerado 0 "território" do bebê e os enfeites, a sua

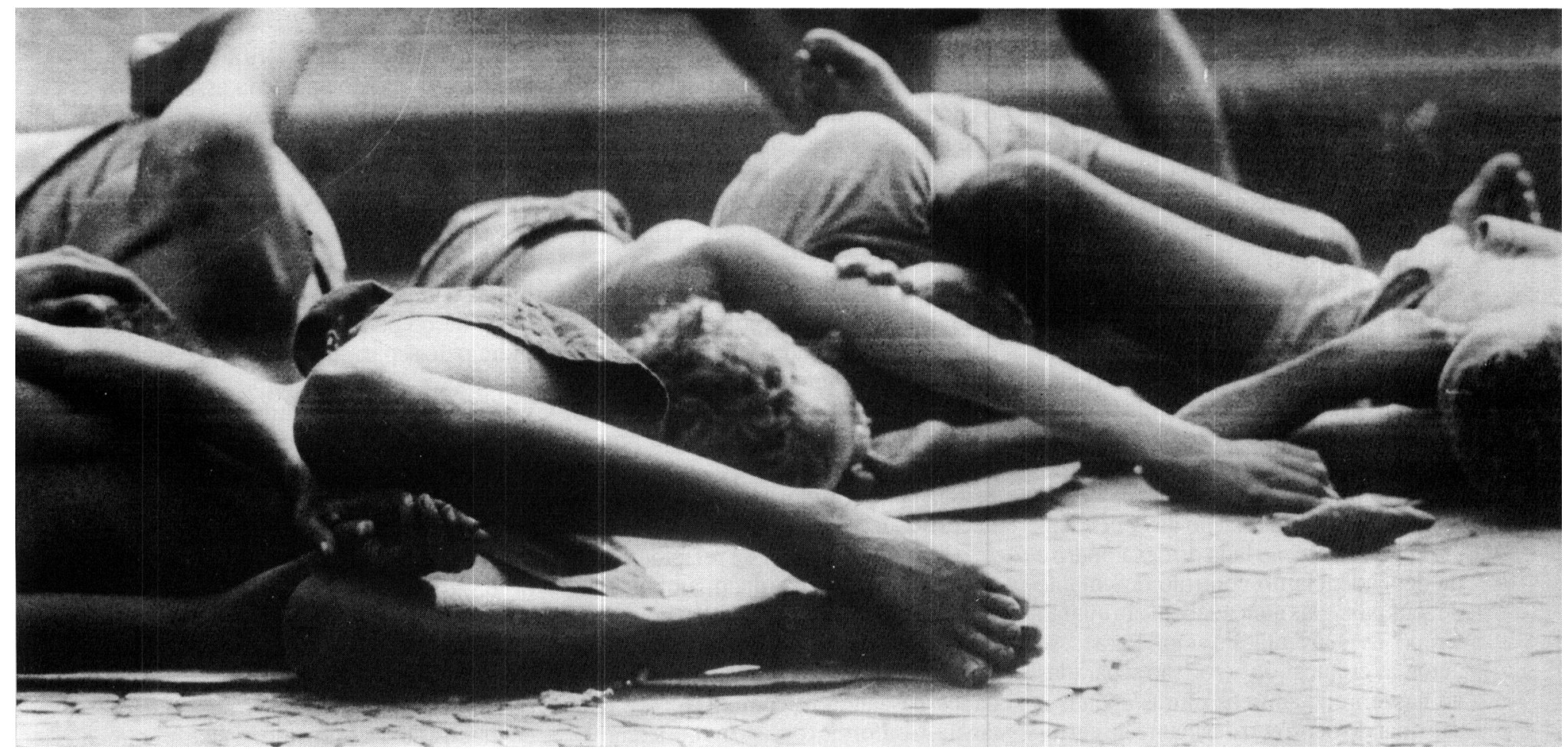




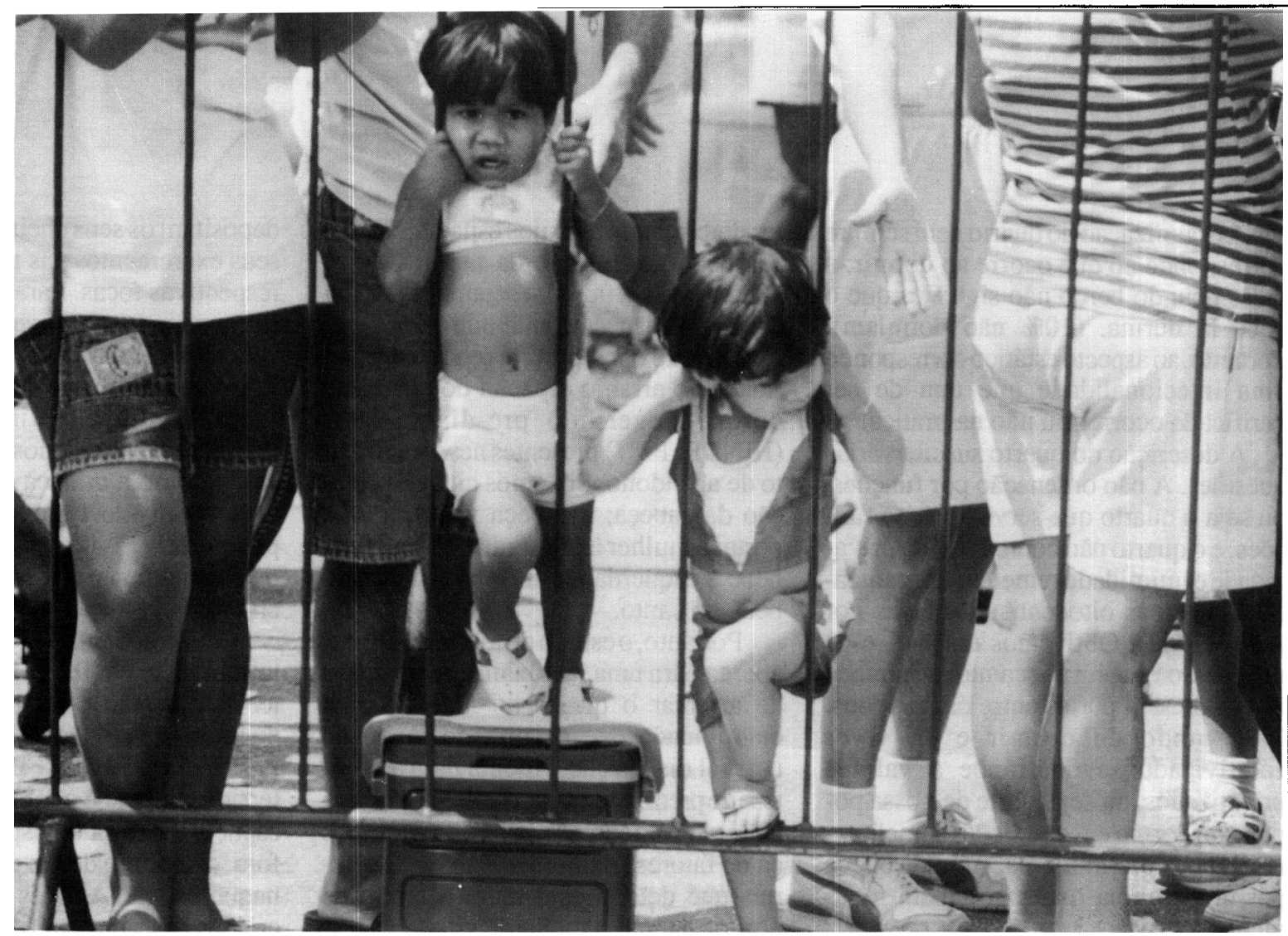

demarcação, o seu "espaçamento". A demarcação territorial de povos coletivizados, como os !Kung se dá na rede de bandos enquanto, à medida que aumenta o índice de privatização, esta vai se dando cada vez mais próxima ao indivíduo. Com a sedentarização, surge a propriedade, e com essa, as posses. A sedentarização também determina o inicio da geometria: a criação do ângulo reto, inexistente na natureza, que surgiu da demarcação da propriedade.

WHITING (1981), descreve que, em climas tropicais os povos tendem a carregar as crianças em tipóias. As crianças usam poucas roupas e dormem próximas à mãe. $O$ oposto ocorre nos climas frios: muitas roupas e o uso do berço. Como consequência do uso do berço, as crianças são separadas de suas mães ao nascer. Se precisam de algo, têm de chorar. Com as crianças da tipóia é como se a criança não tivesse nascido, fosse ainda parte de sua mãe. Elas têm a visão de mundo de sua mãe, que o autor denomina identificação simbiótica. As crianças de berço, ao invés, têm uma relação de dependência ambivalente: ao lado do desamparo e da dependência do controle dominante de seus pais, elas nunca sabem em quanto tempo as suas mães virão. Para esse autor, as crianças de berço são separadas ao nascer, enquanto as outras apenas o são quando ocorrer o desmame de carre- gar e dormir, o que ocorre geralmente aos 2 anos. Assim, as crianças de berço são separadas muito mais "desamparadas" que as outras, ou seja, menos maduras e com menor autonomia. Sua comunicação é distal antes do que proximal, verbal antes do que cinestésica. Estãoem um esquema de reforço retardado e aperiódico.É o que WHITING chama de "dependency hangup", no qual a independência e a auto-confiança são altamente valorizadas, ao mesmo tempo que o comportamento dependente dominante é sutilmente recompensado, mantendo a criança numa posição passiva, por exemplo, precisando chorar e esperar até ser acudida no berço. Este conflito contrasta com os "cross-sex-identity hangup", da cultura da tipóia, em que há uma forte identificação inicial com o papel feminino, dado o bebê ter o ponto de vista maternotanto para meninasquanto para meninos, e em que as crianças são ativas no sentido de perceberem precocemente a sua habilidade para se satisfazerem, por exemplo, mamando ao sentir necessidade.

O modo de dormir se relaciona com o modo de estar acordado, ambos coerentes com o contexto eco-sócio-cultural. A utilização do berço determina, entre outros fatores, um sistema de cuidados baseado em comunicação à distância. Conforme foi visto na nossa amos- tra e em consonância tanto com os!Kung, como com várias outras culturas, o aleitamento contínuo se complementa com o dormir junto à mãe, havendo dois ou três tipos de desmame: do seio, do carregar e do dormir. Esse modelo de cuidar determina um contato contínuo e permanente mãe-criança, com um tipo de contato corporal muito diverso das crianças criadas no berço.

Em nossa pesquisa verificamos que a ausência de berço apareceu associada a desmame tardio enquanto a presença de "cantinho do bebê" estava associada a desmame precoce. Das crianças que desmamaram até 9 meses, 16 possuiam berço e 6 não, enquanto que 8 entre 11 crianças que desmamaram após nove meses não possuiam berço.

$O$ berço pode ser pensado como um indício de separação da mãe. A existência e uso do berço implicaria que a criança estaria separada da mãe em alguma instância, com isso instalando-se o prodomínio da comunicação distal.

Osenfeites podem ser pensados como - modo de possuir os espaços e de defendê-los contrainvadores. DizTUAN (1983) que a mãe é o primeiro lugar da criança, se lugar for definido de um modo amplo como um centro de valor, de alimento e apoio. As crianças tomarse-iam possessivas devido à necessidade de garantir o próprio valor e status entre 


\section{"Vivemos numa}

\section{sociedade afluente em}

que o acúmulo

tecnológico produziu a

chamada sociedade de

consumo, construída

sobre o desenvolvimento

e deseperdício de posses." companheiros. A necessidade de segu rança levaria a apoiar a personalidade em objetos e lugares, o que acabaria por fornecer padrões de identificação através desses apoios. Os enfeites fomeceriam, assim, padrões de identificação.

Vivemos numa sociedade afluente em que o acúmulo tecnológico produziu a chamada sociedade de consumo, construida sobre $\mathrm{o}$ desenvolvimento $\mathrm{c}$ deseperdíciode posses. Segundo MARX (citado emSchneider, 1977): "A propriedade privada tomou-nos tão estúpidos e parciais, que um objeto só é nosso se o possuímos. Daí terem sido todos os sentidos físicos e espirituais substituídos pela simples alienação de todos esses, o sentido de posse". SCHNEIDER (1977) complementa, dizendo que o mundo objetivo dos valores de uso que não se pode "possuir" foi substituido pelo mundo dos fetiches que se pode tão apcnas "adquirir".

Parece-nos muito coerentequeaidentidade dos bebês modernos seja dada por suas "posses", enquanto que em sociedade sem posse, como os !Kung, seja dada por outros parâmetros mais ligados à relação social e ao "corpo materno"

Segundo ARIÈS (1990), na sociedade feudal, o espaço privado era mantido como defesa contra as agressōes do poder público. Era um "privado coletivo", e não um "privado individual" como atualmente. $O$ conceito de privacidade como modo de evitar o perigo pode ser visto também na etologia. $O$ conceito de apego ao próprio território e de espaço pessoal visaria dar conta de comportamentos adaptativos à sobrevivência da espécie (SILVA, Comunicação Pessoal, 1991).

$\mathrm{Na}$ nossa amostra, as casas coletivizadas tendiam a ter poucos enfeites e não ser ordenadas por funçōes enquanto as casas privatizadas eram ordenadas e tinham enfeites. Casas com tendência à ordenação tinham muitos enfeites, aparentemente como mecanismo compensatório ante carências.

O privado pode não ter o sentido de acúmulo, de propriedade, mas, em nossa sociedade, acabou por tê-lo. Para ARIÈS (1990) as marcas das conquistas de uma autonomia pessoal vieram com a aceleração da economia, com o crescimento agrícola e da circulação da moeda, "em que por toda parte se difunde o uso da palavra ganhar. Surgem as arcas como 
indícios de guardar para si, poupar e tornar-se menos dependente de seus familiares. A mobilização das iniciativas e das riquezas suscita a valorização progressiva da pessoa. Instaura-se o medo do corpo porque a natureza é perigosa, ao lado do gosto e preocupação com a limpeza" (p.506).

FREUD (1948) identificou a fase anal com a fase retentiva da ganância econômica: as fezes, como mercadoria de troca entre pessoas, adquirem o caráter acumulativo da sociedade onde a pessoa está inserida. SCHNEIDER (1977) associa o caráter obcessivo-compulsivo à ascenção da burguesia ao poder estatal; ou seja, o poder da "autoridade" burguesa estaria representado em uma organização psico-corporal onde o corpo se encontra delimitado por zonas, limpas/ sujas, superiores/inferiores, e onde se procura o controle de certas partes sobre outras. Para PROST (1992), após o periodo de vida privada familiar, ocorreu e está ocorrendo a vida privada individual onde "o corpo se tomou o lugar de identidade pessoal" (p.105). Esse corpo, que pode ser considerado um corpo "pósmoderno", não tem vergonha de si próprio, "se possui", "se cuida" através do asseio, da dietética e da cultura física. Ao mesmo tempo, há uma "democratização" na vida política e, principalmente, na relação do casal parental entre si e com os filhos. Para este autor, a vida privada individual passou a ser um direito contra a instituição familiar.

\section{Berços, enfeites, casas e famílias}

Os enfeites no berço do bebê podem serconsiderados uma defesa antecipatória dos pais à invasão, e uma afirmação da identidade através da posse. Ao lado do "nome próprio" haveria o "berço próprio" significando não apenas a origem (Brasil: "berço esplendido"); mas o próprio ser (pessoa de "berço").

Observou-se haver uma forte associação entre a quantidade de enfeites na casa e no berço. A mesma dinâmica que dispõe os enfeites da casa disporia os do berço.

A ausência de berço em nossa amostra pode ser considerada como índice de coletivização da criança. Nesse caso, há duas possibilidades: a casa toda ser coletivizada ou apenas o bebê o ser.
Quando a família é coletivizada, podia ocorrer o mesmo que com os !Kung: ausência de enfeites e de berço, e uma rede rica de relaçð̃es sociais. Quando apenas a criança era coletivizada, a questão que se colocou se referiu ao espaço potencial dessa criança: há "lugar" para essa criança na casa? no mundo?

$O$ berço com enfeite pode ser considerado um indicador de privatização da criança e correspondeu ao modo consistente com a sociedade de consumoe seus valores. $O$ berço sem efeite pode indicar um "empobrecimento" do bebê, algum nível carencial a ser verificado em função de estar indicando o corte entre os corpos da mãe/bebê, sem estarem sendo oferecidos substitutos.

\section{O espaço potencial}

Pode-se verificar uma confluência de significados no que se refere ao uso de enfeites para marcar o espaço do bebê e o conceito de espaço potencial de WINNICOTT (1982). Para esse autor, o espaço potencial é o espaço cultural e os objetos transicionais são os intermediários entre os objetos de fantasia e a realidade. Eles tanto ajudam a fazer ponte entre a realidade subjetiva e a realidade objetiva quanto, ao fazê-lo, permitem a criação da própria cultura. $O$ termo

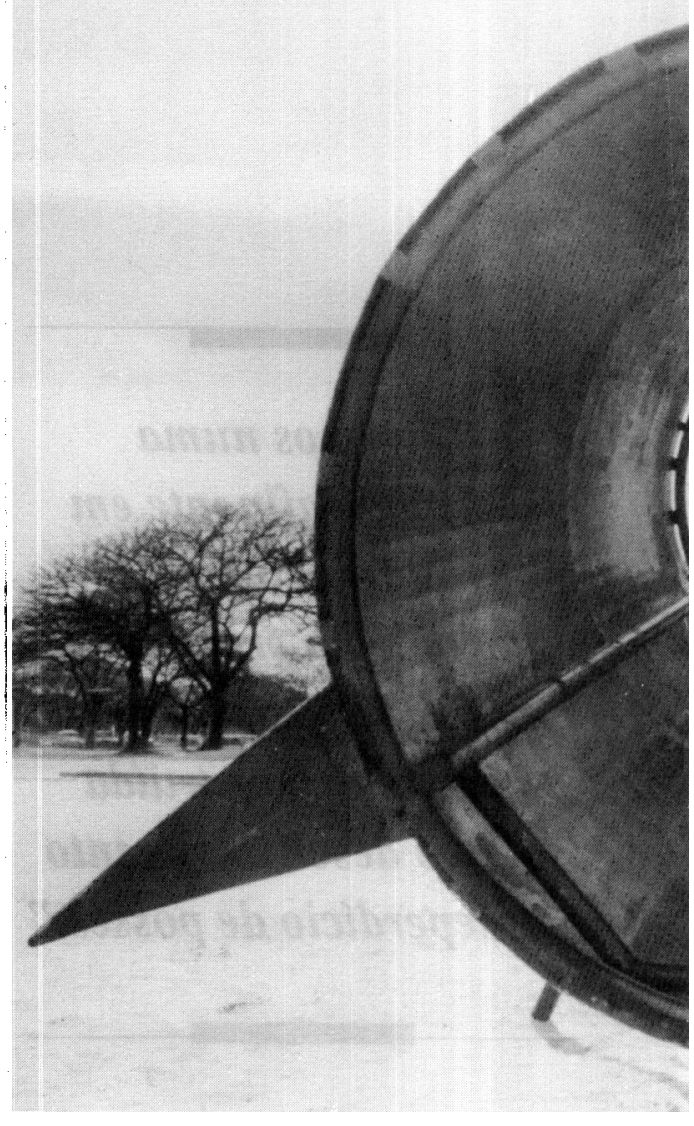

potencial se refere a este aspecto criativo que é, para esse autor, o apanágio da cultura.

Deste modo, da leitura do quar to e do berço pode-se apreender algo o sistema de siginificaçðes que intermedeiam o dentro e o fora, o mundo objetivo e o mundo subjetivo, e perceber como a "brecha", o locus da cultura, está sendo preenchida.

O estudo do quarto de dormir revela arranjos particulares ao lado de irregularidades indicando quer a ação de fatores específicos à organização familiar quer no contexto sócio-cultural no qual a família está inserida.

$\mathrm{Na}$ forma em que a relação mãecriança é apresentada, isto é, no berço, berço com enfeites, ausência de berço, estaria co-representado o contex to dos valores sócio-culturais onde ocorreria o desenvolvimento da criança tanto em função dos tipos de interações que dele decorrem quanto da internalização dos padrões que a ele presidem.

Este trabalho é parte da dissertaçāo de mestrado intitulado "Modo de Vida e Relaçäomäe-criança: o mamare oandar, omodo de morar e o modo de dormir", Instituto de PsicologialUSP, orientadora: Ana Maria Almeida Carvalho. 


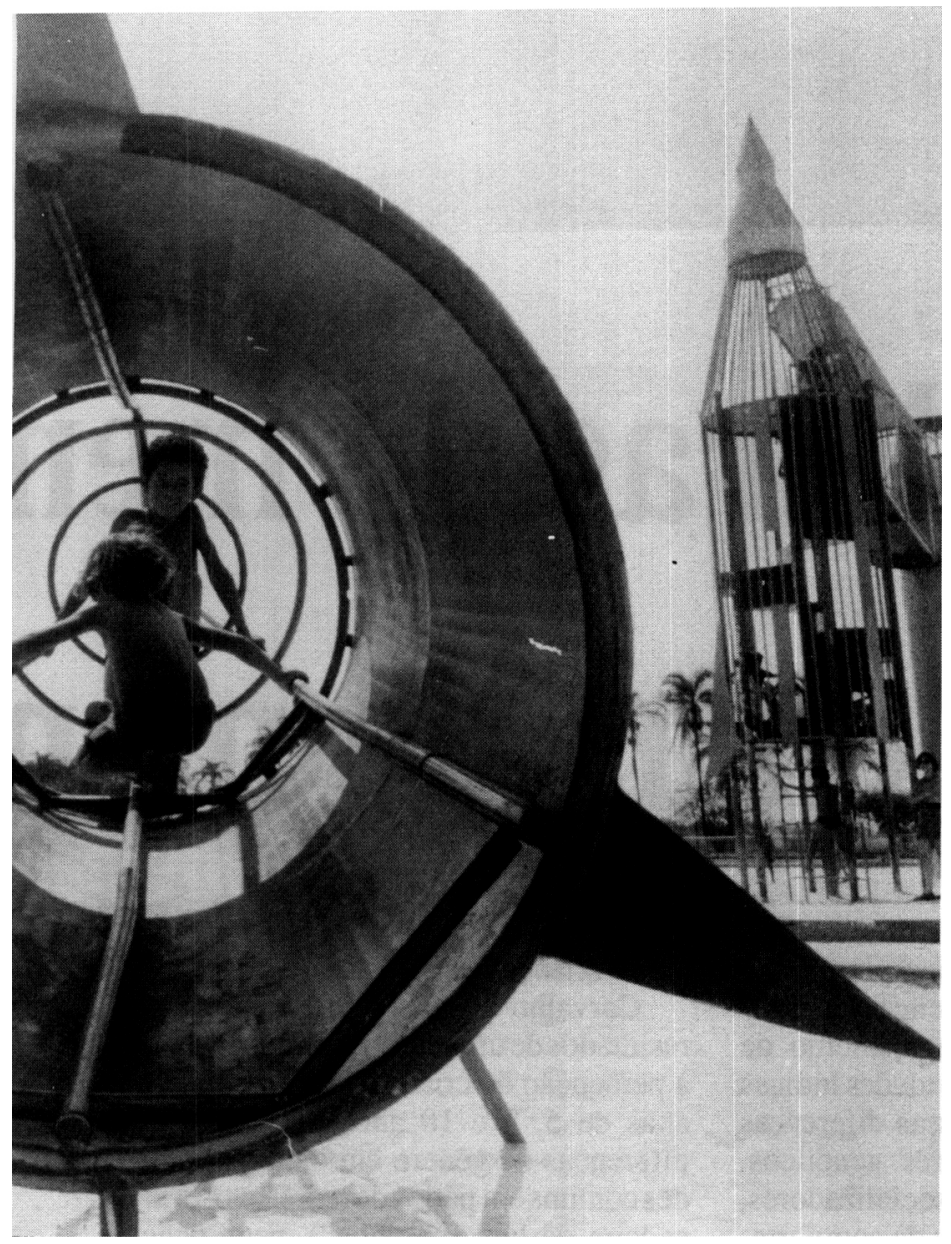

\section{Bibliografia}

ARIÈS, P.: História Social da Criança e da Familia, Ed. Guanabara, Rio de Janeiro, 1978

ARIĖS, P. e DUBY, E (ed) História da Vida Privada, da Europa Feudal à Renascença, vol.2, Companhia das Letras, Säo Paulo, 1990).

ARIÈS e DUBY, E. (ed) História da Vida Privada, da Renascença ao Século das Luzes, vol 3, Companhia das Letras, São Paulo, 1991

DIBIE,P.OQuarto de Dormir: um estudo etnológico, Ed Globo, Rio de Janeiro, 1988.

EIBL-EIBENFELDT, I: $O$ mito dos caçadores-coletores não agressivos, in Holloway, $R$. L. (ed) Primate Agression, territoriality and xenophonia, Academic Press, Londres, 1974.

FREUD, S.: Uma teoria sexual in "Obras Complexas" cap. VII, Ed. Biblioteca Nueva, Madrid, 1948.

HINDE,R.A.:Individuals, Relationshipsand Cultures: links between Ethology and the Social Sciences, Cambridge University Press, Cambridge, 1987.

JOUVET, M.: Neurologia do Sonho, in A Unidade do Homem, vol II, O Cérebro Humano e seus Universais. Centro Royaumont para uma ciência do Homem, Ed. Cultrix e Ed. Universidade de S. Paulo, São Paulo, 1978.

MOLES, A.: Ecologia dos Atos, in Centro Royaumont para uma Ciência do Homem (ed): A Unidade do Homem vol III, Para uma Antropologia Fundamental, Ed. Cultrix e Ed. da Universidade de São Paulo, 1978.

" $O$ berço com enfeite pode ser considerado um indicador de privatização da criança $e$ correspondeu ao modo consistente com a sociedade de consumo e seus valores." MORRIS, D.: Você, Círculo do Livro, São Paulo. 1977.

MORRIS, D.: O Macaco Nu. Record, Rio de Janeiro, 1967 .

PROST, D.:Fronteiras e espaço do privado: A familia e o individuo, in ARIES, P. e DUBY, G. (dir) História da vida privada. Volume 5, Companhia das Letras, São Paulo, 1992.

RABINOVICH, E.P.: "A Casa dos Sem Casa”, 1992, no prelo.

RABINOVICH, E.P.: “O nascimento psicologico", $R$. Bras. CDH, Säo Paulo, número 1, 1991.

SCHNEIDER, M.: Neurose e Classes Sociais. Uma Sintese Freudiana - Marxista, Zahar Ed., Rio de Janeiro, 1977

SIQUEIRA, A A.F.: OLIVEIRA, D.C; RABINOVICH, E.P.; SANTOS, N.G.: :"Instrumentos para o Acompanhamento e A valiação do Desenvolvimento Infantil na Atenção Prinária à Saúde". Rev. Bras. Cresc. Des. Hum, ano II, $n^{2} 2,1992$.

WINNICOTT, D.W.:DaPediatrià̀ Psicanalise, Francisco Alves, Rio de Janeiro, 1982.

WHITING C., J.W. M.: Environamental Constraints on Infant Care Pratice, in MUNROE, MUNROE and WHITING (eds): Handbook of Cross - Cultural Human Development, Garldan Press, New York, 1981. 